\title{
QUALIDADE FISIOLÓGICA DE SEMENTES DE Peltophorum dubium (Sprengel.) Taubert CLASSIFICADAS PELO TAMANHO
}

\author{
PHYSIOLOGICAL QUALITY OF Peltophorum dubium (Sprengel.) Taubert SEEDS \\ CLASSIFIED BY SIZE
}

\author{
Matheus Santin Padilha ${ }^{1}$, Neymar Matheus De Donatto ${ }^{1}$, Lúcia Salengue Sobral ${ }^{1}$ \\ ${ }^{1}$ Universidade Comunitária da Região de Chapecó - Unochapecó, Chapecó, Santa Catarina, Brasil - \\ matheus_santin@hotmail.com,neymar@unochapeco.edu.br\&luciass@unochapeco.edu.br
}

\section{RESUMO}

\begin{abstract}
Uma estratégia adaptativa das espécies florestais contra fatores imprevisíveis do ambiente é a oscilação na produção anual e no tamanho das sementes. Neste sentido, diversos estudos têm buscado investigar a influência do tamanho das sementes na germinação e vigor. As pesquisas sobre a relação entre tamanho e qualidade fisiológica das sementes podem contribuir para a criação de estratégias para a seleção de sementes destinadas ao processo de produção de mudas. $O$ trabalho teve como objetivo avaliar a qualidade fisiológica das sementes de Peltophorum dubium classificadas pelo tamanho. O lote de sementes foi separado e pesado em três classes de tamanho: pequenas $(<$ $0,0501 \mathrm{~g})$, médias $(0,0501-0,0600 \mathrm{~g})$ e grandes (>0,0600 g). O delineamento experimental foi o inteiramente casualizado com oito repetições. Os parâmetros avaliados foram: plântulas normais e anormais, sementes duras e mortas, primeira contagem de germinação, índice de velocidade de germinação, tempo médio de germinação, uniformidade de germinação, comprimento de plântulas, massa seca de plântulas e índice de vigor. Houve diferença significativa entre as variáveis analisadas, sendo possível identificar diferenças na qualidade fisiológica entre as classes de tamanho. Com os resultados foi possível identificar que as sementes com menor tamanho apresentaram maior intensidade de dormência; as sementes de tamanho médio demonstraram maior qualidade fisiológica e, as sementes de tamanho grande apresentam maior potencial para formação de plântulas com maior massa seca.
\end{abstract}

PALAVRAS-CHAVE: Fabaceae, Germinação, Massa de sementes, Vigor de sementes.

\section{ABSTRACT}

An adaptive strategy of forest species against unpredictable environmental factors is the fluctuation in annual production and seed size. In this sense, several studies have sought to investigate the influence of seed size on germination and vigor. Research on the relationship between seed size and physiological quality can contribute to the creation of strategies for the selection of seeds to the seedling production process. The work aimed to evaluate a physiological quality of the seeds of Peltophorum dubium classified by size. The seed lot separated and weighed in three size classes: small (<0.0501 g), medium ( $0.0501-0.0600 \mathrm{~g}$ ) and large (>0.0600 g). The experimental design was completely randomized with eight replications. The parameters obtained were: normal and abnormal seedlings, hard and dead seeds, first germination count, germination speed index, average germination time, germination uniformity, seedling length, seedling dry mass and vigor index. There was a significant difference between the variables analyzed, making it possible to identify differences in physiological quality between size classes. With the results it was possible to identify that the seeds with smaller size have greater dormancy intensity; medium sized seeds showed greater physiological quality, and large sized seeds have greater potential for seedling formation with greater dry mass.

KEYWORDS: Fabaceae, Germination, Seed mass, Seed vigor. 


\section{INTRODUÇÃO}

As espécies florestais podem apresentar uma variação na produção e tamanho das sementes, sendo essa, uma estratégia adaptativa contra fatores imprevisíveis após a sua dispersão (RUBIO DE CASAS et al., 2017). A partir disso, muitos estudos são realizados buscando investigar as consequências dessa variação na germinação de sementes, crescimento e sobrevivência das plantas a campo (WANG \& IVES, 2017). A principal forma de propagação das espécies florestais nativas é através do uso de sementes, por esse motivo, é pertinente a identificação dos fatores de influência durante a produção de mudas (DIAS et al., 2012).

As informações existentes na literatura sobre a qualidade fisiológica de sementes florestais relacionadas ao tamanho de sementes são divergentes. Para algumas espécies florestais o tamanho da semente é um indicativo da sua qualidade fisiológica (SILVA et al 2017; ATTRI et al., 2017). Contudo, Neto \& Paula (2017) destacam que as correlações entre as características biométricas das sementes e a qualidade fisiológica são baixas.

Segundo Carvalho \& Nakagawa (2012), em geral, as sementes de maior tamanho possuem maior quantidade de reservas que foram acumuladas durante o seu desenvolvimento. A partir disso, foi verificado que as sementes com maior tamanho apresentaram maior qualidade fisiológica de sementes de Sideroxylon obtusifolium (SILVA et al., 2015) e Prunus persica (SOUZA et al., 2016; SOUZA et al., 2017). Entretanto, ALMEIDA et al. (2014) verificaram que as sementes de Amburana cearenses de maior tamanho apresentaram menor qualidade fisiológica. Em contrapartida, Mtambalika et al., (2014) destaca que o tamanho de sementes não possui relação com a qualidade fisiológica, mas no geral favorece a produção de plântulas com maior vigor.

Os estudos referentes às espécies florestais com potencial de uso e a forma como as mudas serão produzidas são de importância significativa para garantir o sucesso da implantação e/ou revitalização das áreas (FARIA et al., 2015). Nesse sentido, o uso de sementes com alta qualidade fisiológica é importante para o processo de produção de mudas com maior qualidade para atender o setor florestal.

A Peltophorum dubium (Speng.) Taubert é uma espécie florestal nativa conhecida como canafístula, pertence à família Fabaceae, que possui ocorrência principalmente na Floresta Estacional Decidual. Apresenta crescimento rápido, potencial madeireiro e ecológico, sendo amplamente utilizada na restauração de áreas degradadas e arborização urbana (CORADIN et al., 2011).
Considerando que os aspectos biométricos de sementes podem exercer influência sobre a sua qualidade fisiológica, é pertinente identificar as relações entre essas características, dando subsídios para que os viveiros florestais realizem a seleção e beneficiamento das sementes coletadas visando a maior qualidade fisiológica. Dessa forma, o trabalho teve como objetivo avaliar a qualidade fisiológica de sementes de $P$. dubium classificadas pelo tamanho, buscando identificar as diferenças e as relações proporcionadas por essa característica durante a germinação e formação das plântulas.

\section{MATERIAL E MÉTODOS}

A coleta dos frutos de $P$. dubium foi realizada em oito árvores matrizes localizadas em um remanescente florestal no distrito de Marechal Bormann zona rural do município de Chapecó, Santa Catarina, localizado nas coordenadas 27인ㄱ"S e 5239"52"O. O distanciamento entre as matrizes selecionadas para a coleta foi de $100 \mathrm{~m}$ e os frutos coletados quando apresentavam coloração marrom clara. Após a coleta o material foi encaminhado ao Laboratório de Análise de Sementes da Área de Ciências Exatas e Ambientais da Universidade Comunitária da Região de Chapecó - Unochapecó.

A extração das sementes dos frutos foi realizada de forma manual sendo classificadas a partir da eliminação das sementes imaturas, deterioradas e danificadas. As sementes das oito matrizes foram homogeneizadas formando um único lote de sementes, e posteriormente armazenadas em câmara seca $\left(16 \pm 2^{\circ} \mathrm{C}\right.$ e $55 \pm 5 \%$ de umidade relativa) por seis meses até o início das análises.

As sementes do lote foram pesadas individualmente em balança analítica com precisão de 0,0001g, as quais foram classificadas em: pequenas $(<0,0501 \mathrm{~g})$, médias $(0,0501-0,0591 \mathrm{~g})$ e grandes $(>0,0591 \mathrm{~g})$. Para a definição das classes foi realizada a pesagem de 400 sementes e realizado o histograma de frequência (Figura $1 \mathrm{~A}$ ) e as classes foram definidas com base no gráfico de boxplot (Figura 1B). A classe pequena foi representada pelas sementes com massa abaixo do primeiro quartil, a classe média pelas sementes com massa entre o primeiro e o terceiro quartil, e a classe grande pelas sementes com massa acima do terceiro quartil.

A pesagem ocorreu até que se obtivesse $100 \mathrm{~g}$ de sementes de cada classe. Após essa definição, determinouse o peso de mil sementes utilizando oito repetições de 100 sementes (BRASIL, 2009). Depois de obtida a amostra de cada tamanho, com o auxílio de paquímetro digital 
determinou-se as dimensões das sementes (comprimento, largura e espessura), utilizando 50 sementes por classe (Tabela 1).

A.

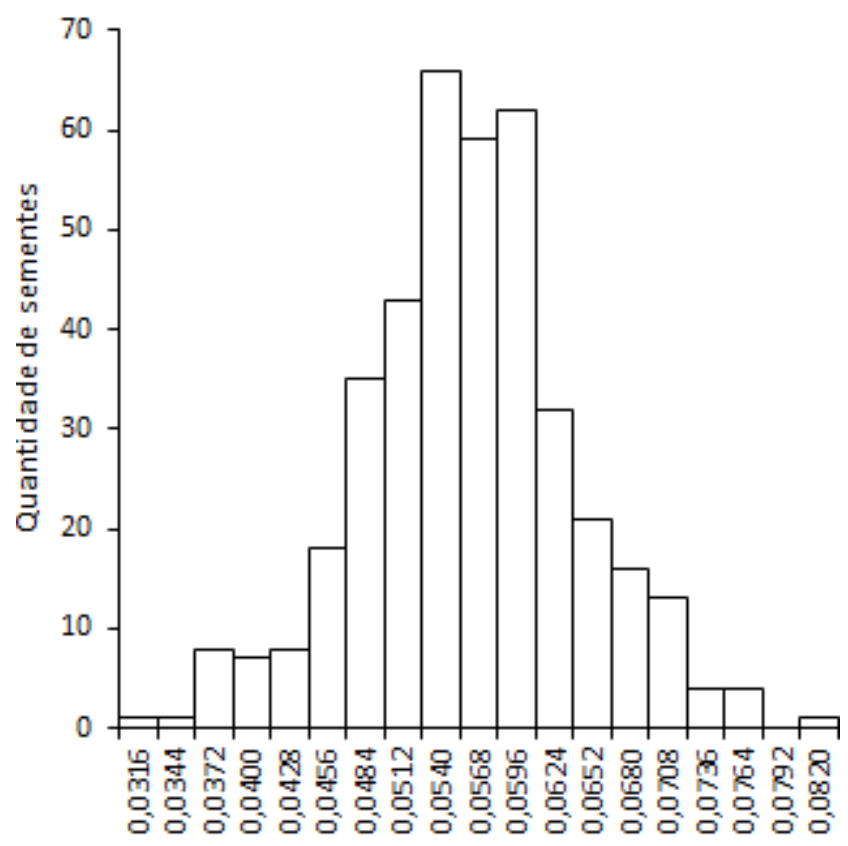

B.

Massa das sementes $(\mathrm{g})$

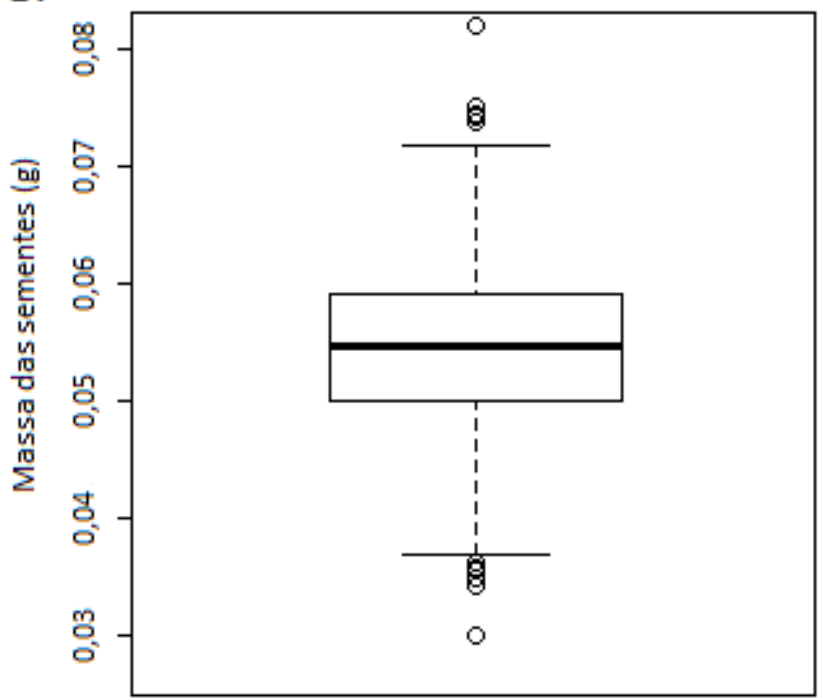

Figura 1. Histograma de frequência (A) e distribuição boxplot (B) utilizadas para a definição das classes de tamanho das sementes do lote de $P$. dubium.

Para a determinação do grau de umidade, foram utilizadas duas repetições de $5 \mathrm{~g}$ de sementes de cada classe, sendo posteriormente, acondicionadas em cápsulas de alumínio e levadas à estufa a 105 으, durante $24 \mathrm{~h}$ (BRASIL, 2009).

O tratamento para superação da dormência foi o mesmo para as três classes de sementes, sendo elas submetidas à imersão em $\mathrm{H}_{2} \mathrm{SO}_{4}$ (96\%) por 10 min (PIROLI et al., 2005), e em seguida lavadas com água destilada. Após a superação da dormência as sementes foram submetidas à assepsia com a imersão em hipoclorito de sódio a $2 \%$ durante $5 \mathrm{~min}$, e posteriormente lavadas com água destilada.

Tabela 1. Médias e desvio padrão do comprimento (C), largura (L), espessura (E) e peso de mil (PMS) das classes de sementes pequena média e grande de $P$. dubium pré-selecionadas.

\begin{tabular}{cccc}
\hline & \multicolumn{3}{c}{ Classes de tamanho } \\
\cline { 2 - 4 } Avaliação & Pequena & Média & Grande \\
\hline C (mm) & $8,98 \pm 0,47$ & $9,74 \pm 0,48$ & $10,26 \pm 0,46$ \\
L (mm) & $3,85 \pm 0,22$ & $4,11 \pm 0,26$ & $4,70 \pm 0,29$ \\
E (mm) & $1,85 \pm 0,14$ & $1,92 \pm 0,12$ & $2,13 \pm 0,22$ \\
PMS (g) & 45,49 & 55,56 & 66,83 \\
\hline
\end{tabular}

A avaliação do teste de germinação foi realizada diariamente, contabilizando as plântulas normais (PN), plântulas anormais (PA), sementes mortas (SM) e sementes duras (SD). O teste foi conduzido em germinador Mangelsdorf, em regime de luz constante em temperatura de $25 \pm 2 \stackrel{\circ}{ }$, sendo a semeadura realizada em substrato papel toalha na forma rolo, o qual foi umedecido com volume de água equivalente a 2,5 vezes o seu peso seco (BRASIL, 2013). A primeira contagem de germinação (PCG) foi determinada no quarto dia após a montagem do teste.

Para calcular o índice de velocidade de germinação (IVG) foram utilizados os dados de plântulas normais contabilizadas a cada dia. O cálculo foi realizado pelo somatório do número de plântulas normais $\left(G_{i}\right)$ a cada dia, dividido pelo número de dias $\left(\mathrm{N}_{\mathrm{i}}\right)$ decorridos entre a semeadura e a germinação conforme a fórmula proposta por Maguire (1962):

$$
I V G=\sum\left(G_{i} / N_{i}\right)
$$

Com os dados obtidos foi determinado o tempo médio de germinação (TMG), o qual é expresso em dias e calculado através da equação proposta por Labouriau (1983), considerando o número de sementes germinadas no intervalo entre cada contagem $\left(\mathrm{n}_{\mathrm{i}}\right)$ e o tempo decorrido entre o início da germinação e a i-ésima contagem $\left(t_{i}\right)$, sendo:

$$
T M G=\sum\left(n_{i} t_{i}\right) / \sum n_{i}
$$

O tempo requerido para a germinação de $90 \%$ das sementes (T90) (FAROOQ et al., 2005) e a uniformidade de 
germinação (UnifG) (CASTAN et al., 2018), foram calculados com o auxílio do software $R$ ( $R$ CORE TEAM, 2019) utilizando o pacote SeedCalc elaborado por Silva et al. (2019).

A avaliação do comprimento e massa seca de plântulas foi realizada em diferentes períodos de tempo (96, 120, 144 e 168 horas após a montagem do teste).

$O$ teste de desempenho de plântulas foi realizado utilizando oito repetições de 20 sementes em germinador Mangelsdorf com regime de luz constante e temperatura de $25 \pm 2$ o $C$. Utilizou-se papel toalha na forma de rolo umedecido com volume de água equivalente a 2,5 vezes a sua massa seca em água, sendo os rolos mantidos na vertical dentro do germinador. Após cada período foi determinado o comprimento de plântulas (CP) com o auxílio de régua graduada em milímetros. Os resultados foram expressos em cm.plântula ${ }^{-1}$. A massa seca de plântulas (MSP) foi realizada de 10 plântulas avaliadas no teste de comprimento descrito anteriormente. As plântulas foram secas à temperatura de 80 ㅇ por $24 \mathrm{~h}$. $\mathrm{O}$ peso das amostras foi realizado em balança analítica $(0,0001 \mathrm{~g})$ sendo os resultados expressos em mg.plântula ${ }^{-1}$ (NAKAGAWA, 1999).

A densidade de biomassa (DEN) foi determinada conforme proposto por Pereira et al., (2009). Foi utilizado a MSP e o CP, obtidos em 168 horas de germinação, sendo expressa em miligramas por centímetro de plântula (mg $\left.\mathrm{cm}^{-1}\right)$, calculado pela equação:

$$
\mathrm{DEN}=\mathrm{MSP}(\mathrm{mg}) / \mathrm{CP}(\mathrm{cm})
$$

Foram determinados dois índices de vigor propostos por Abdul-Baki \& Anderson (1973), sendo o Índice de Vigor I calculado por:

$$
\text { VIGORI }=P N(\%) \times C P(\mathrm{~cm})
$$

E o índice de vigor Il calculado por:

$$
\text { VIGOR II = PN (\%) } \times \text { MSP }(\mathrm{mg})
$$

O experimento foi conduzido em delineamento experimental inteiramente casualizado com oito repetições. Os resultados foram submetidos à análise de variância (teste $\mathrm{F}$ ) pelo software Assistat versão 7.7 beta, e a comparação entre as médias foram efetuadas através do teste de Tukey a $5 \%$ de probabilidade. A execução da análise de componentes principais ( $A C P$ ) foi realizada utilizando o software R (R CORE TEAM, 2019).

\section{RESULTADOS E DISCUSSÃO}

As sementes de tamanho pequeno, médio e grande, apresentaram grau de umidade 9,$2 ; 9,4$ e $10,1 \%$ respectivamente, indicando que o equilíbrio higroscópico apresentou diferença entre os tamanhos. Alves et al., (2005), também verificaram diferenças no teor de umidade de sementes de Mimosa caesalpiniifolia classificadas em classes de tamanho, entretanto, a diferença de umidade entre as sementes não compromete os resultados dos testes fisiológicos, uma vez que, é inferior a $2 \%$, como estabelecido pela literatura (MARCOS-FILHO, 1999).

Os resultados obtidos demonstram que houve diferença significativa para as variáveis $P N, P A, S D, S M$, TMG, T90, UnifG, CP, MSP, DEN, VIGOR I e VIGOR II, sendo as médias apresentadas na tabela 2 . Não foi verificado diferença significativa para as variáveis PCG e IVG.

Tabela 2. Médias obtidas para as variáveis analisadas entre as classes de sementes pequena, média e grande de $P$. dubium.

\begin{tabular}{cccccc}
\hline Classe & PCG & PN & PA & SM & SD \\
\hline Pequena & $46 \mathrm{a}^{*}$ & $74 \mathrm{ab}$ & $5 \mathrm{a}$ & $4 \mathrm{~b}$ & $17 \mathrm{a}$ \\
Média & $51 \mathrm{a}$ & $79 \mathrm{a}$ & $9 \mathrm{a}$ & $8 \mathrm{ab}$ & $5 \mathrm{~b}$ \\
Grande & $52 \mathrm{a}$ & $70 \mathrm{~b}$ & $20 \mathrm{~b}$ & $9 \mathrm{a}$ & $2 \mathrm{~b}$ \\
\hline CV \% & 13,42 & 9,31 & 33,41 & 27,84 & 34,70 \\
\hline Classe & IVG & TMG & T90 & UnifG & CP \\
\hline Pequena & $8,2 \mathrm{a}$ & $4,68 \mathrm{ab}$ & $5,8 \mathrm{~b}$ & $2,6 \mathrm{~b}$ & $10,15 \mathrm{~b}$ \\
\hline Média & $8,7 \mathrm{a}$ & $4,76 \mathrm{a}$ & $6,3 \mathrm{a}$ & $3,2 \mathrm{a}$ & $11,45 \mathrm{a}$ \\
Grande & $8,0 \mathrm{a}$ & $4,50 \mathrm{~b}$ & $5,6 \mathrm{~b}$ & $2,5 \mathrm{~b}$ & $9,85 \mathrm{~b}$ \\
\hline CV \% & 8,00 & 3,81 & 5,87 & 12,28 & 8,40 \\
\hline Classe & MSP & DEN & VIGOR I & VIGOR II \\
\hline Pequena & $9,58 \mathrm{c}$ & $0,94 \mathrm{~b}$ & $751 \mathrm{~b}$ & $709 \mathrm{~b}$ \\
\hline Média & $11,53 \mathrm{~b}$ & $1,01 \mathrm{~b}$ & $904 \mathrm{a}$ & $914 \mathrm{a}$ \\
\hline Grande & $13,06 \mathrm{a}$ & $1,33 \mathrm{a}$ & $688 \mathrm{~b}$ & $911 \mathrm{a}$ \\
\hline CV \% & 7,07 & 8,36 & 12,38 & 10,99 \\
\hline
\end{tabular}

* Médias seguidas da mesma letra na coluna, não diferem entre si pelo teste de Tukey a $5 \%$ de probabilidade. Primeira contagem de germinação (PCG); plântulas normais (PN); plântulas anormais (PA); sementes mortas (SM), sementes duras (SD); índice de velocidade de germinação (IVG); tempo médio de germinação (TMG); tempo necessário para a germinação de $90 \%$ das sementes (T90); uniformidade de germinação (UnifG); comprimento de plântulas (CP); massa seca de plântulas (MSP); densidade de biomassa (DEN); índice de vigor I (VIGOR I) e; índice de vigor II (VIGOR II). CV \%: Coeficiente de variação.

As sementes da classe grande apresentaram a menor porcentagem de PN quando comparada as sementes médias, e maior porcentagem de PA em relação às sementes pequenas e médias. Esses resultados demonstram diferenças na qualidade fisiológica entre as 
classes de tamanho de sementes. Resultados semelhantes foram obtidos por Almeida et al. (2014), em que as sementes grandes de Amburana cearensis apresentaram menor porcentagem de plântulas normais em relação as sementes de classe pequena e média.

Mesmo com essa diferença, a literatura apresenta diversos estudos em que o número de plântulas normais não possui associação com o tamanho de sementes (ALVES et al., 2005; MTAMBALIKA et al., 2014; MISSANJO \& MAYA, 2015; MISSANJO \& MKWEZALAMBA, 2015; BISPO et al., 2017), e essa relação entre o tamanho de sementes e a porcentagem de plântulas normais é variável com o local de coleta (ALVES et al., 2005; SOUZA et al., 2017), com a idade da planta matriz (BISHT et al., 2016), com as condições ambientais entre os anos de coleta (BISPO et al., 2017) e não necessariamente o tamanho das sementes.

Em relação à porcentagem de SD (Tabela 2), houve diferença entre as três classes de sementes, sendo que as sementes pequenas apresentaram maior porcentagem. A diferença para SD ocorre devido às sementes que são dispersas por uma mesma planta possuem diferentes intensidades de dormência, e frequentemente a variação dessa dormência é demonstrada na aparência das sementes ou em cada semente em termos de cor, tamanho e espessura do tegumento (BEWLEY et al., 2013). Considerando o tamanho, as sementes de menor tamanho possuem maior intensidade de dormência dentro de uma população (MARCOS-FILHO, 2015).

O tamanho de sementes e a dormência estão relacionados no sentido evolucionário de perpetuação da espécie, em que, as sementes com maior tamanho são menos dependentes da dormência (RUBIO DE CASAS et al., 2017). Essa relação pode explicar a maior presença de sementes duras na classe de sementes pequenas em relação às sementes médias e grandes, mesmo após passar pelo tratamento de superação da dormência. Em complemento, a diferença na intensidade de dormência dentro do lote sugere que o mesmo tratamento para superação de dormência física pode ser prejudicial para as diferentes classes de tamanho de um lote.

Müller et al. (2016) verificaram que a dormência de $P$. dubium é variável entre diferentes matrizes, em que, utilizando o mesmo tratamento com ácido sulfúrico $\left(\mathrm{H}_{2} \mathrm{SO}_{4}\right)$ por 15 minutos foi benéfico ou prejudicial para a porcentagem de germinação quando comparado a testemunha. Dessa forma, é possível que o tratamento utilizado neste estudo para a superação da dormência das sementes $\left(\mathrm{H}_{2} \mathrm{SO}_{4}\right.$ por 10 minutos) tenha causado a maior porcentagem de plântulas anormais e sementes mortas dentro do lote classificado como grande e, insuficiente para superar totalmente a dormência do lote de sementes pequenas (Tabela 2).

Os parâmetros associados à velocidade de germinação (i.e., TMG e T90), indicam que a classe de sementes médias germinou com maior velocidade, sendo da mesma forma, mais uniforme (UnifG) durante o processo de germinação, o que favoreceu a formação de plântulas com maior CP (Tabela 2). A velocidade de germinação e a uniformidade são parâmetros considerados para o vigor de um lote de sementes, sendo importantes durante o estabelecimento das plantas (MARCOS-FILHO, 2015), da mesma forma, sementes com maior vigor, apresentam maior comprimento nos testes de desempenho de plântulas (KRZYZANOWSKI et al., 2018).

As sementes com maior tamanho apresentaram maior MSP, indicando influência do tamanho na mobilização de biomassa. Da mesma forma, as sementes de maior tamanho formaram plântulas com maior densidade de biomassa (i.e., as plântulas apresentaram menor CP e maior MSP) em relação à classe de semente média (Tabela 2). Artigos na literatura ressaltam que o tamanho da semente apresenta correlação positiva com a formação de plântulas de maior massa seca (MTAMBALIKA et al., 2014; PEREIRA et al., 2015), sendo necessário utilizar outros parâmetros que não tenham correlação com a massa seca de sementes para determinar a mobilização das reservas e a qualidade fisiológica (ANDRADE et al., 2019).

$A$ relação entre o tamanho das sementes durante $O$ crescimento de plântulas (i.e. CP e MSP) de $P$. dubium mostra que no início das avaliações (96 horas) as sementes não apresentam diferenças no $\mathrm{CP}$, contudo as sementes pequenas apresentaram a menor MSP nesse período. No decorrer do teste de desempenho de plântulas as sementes de tamanho médio apresentaram maior comprimento a partir de 144 horas após a montagem do teste (Figura 2A), contudo, apresentam menor massa seca em relação às sementes grandes nesse mesmo período (Figura 2B).

Resultados semelhantes foram obtidos por Alves et al., (2005) e Silva et al. (2015), em que sementes de classe grande de Mimosa caesalpinifolia e Sideroxylon obtusifolium respectivamente, apresentaram maior massa seca de plântulas em relação às sementes de tamanho médio e pequeno. A associação entre a maior massa seca de plântulas oriundas de sementes grandes segundo Carvalho \& Nakagawa, (2012) é devido a maior quantidade de reservas disponíveis que são destinadas à formação da plântula. Com isso, pode-se dizer que as sementes de maior tamanho forneceram maior quantidade de reservas para o eixo embrionário, resultando em plântulas com 
maior massa seca. Isso vai de encontro ao observado por Pereira et al., (2015), onde destacam que o resultado da maior massa seca de plântulas originada pelas sementes de tamanho grande, é devido a maior capacidade de reduzir (em quantidade) as reservas armazenadas durante o período de formação da plântula, o que favorece o desenvolvimento inicial e emergência no campo.
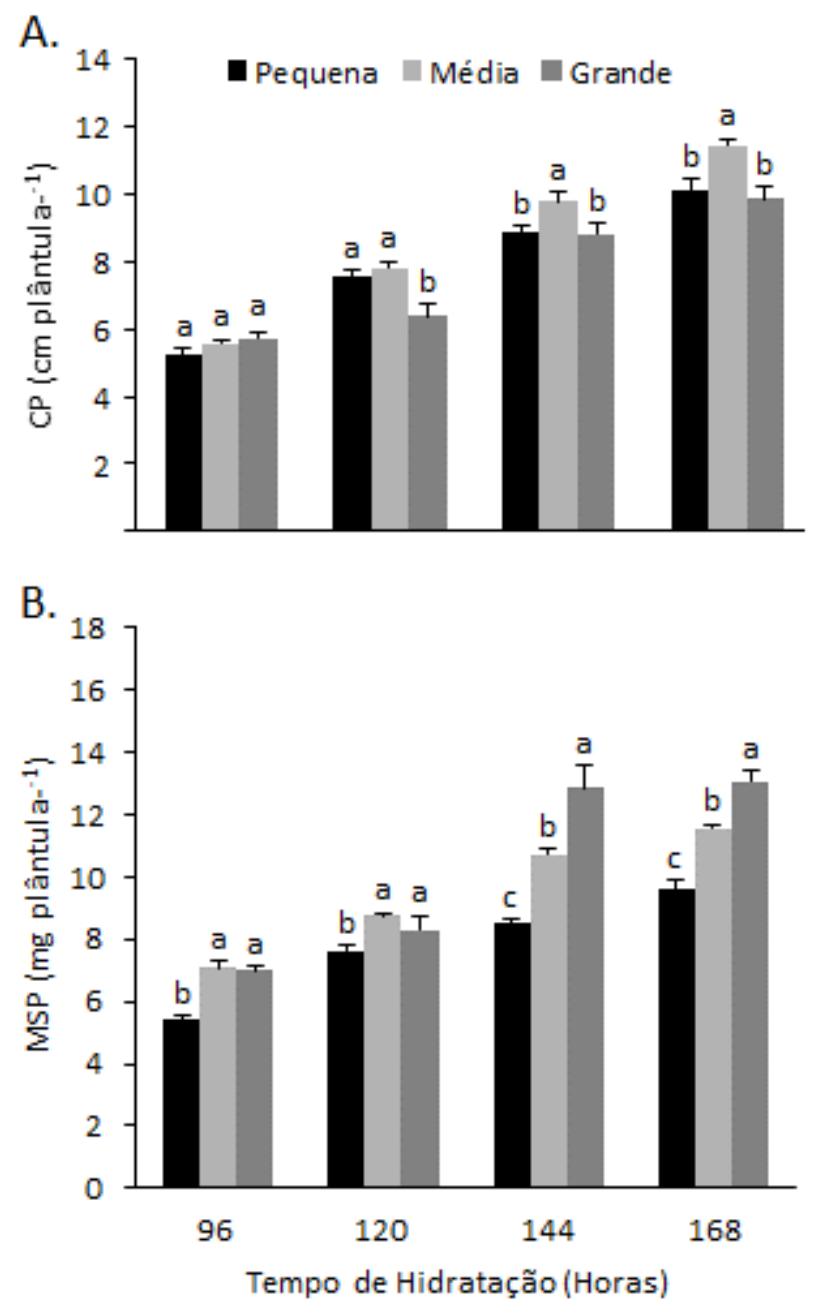

Figura 2. Comprimento de plântulas (CP) e massa seca de plântulas (MSP) avaliadas nos tempos de 96, 120, 144 e 168 horas de hidratação após a semeadura das diferentes classes de tamanho das sementes de $P$. dubium. Médias seguidas de mesma letra minúscula dentro do tempo não diferem estatisticamente entre si pelo teste de Tukey a $5 \%$ de probabilidade.

Considerando os resultados obtidos para as sementes grandes, mesmo apresentando maior MSP em 168 horas de germinação (Figura 2B), os resultados de PN, TMG, UnifG (Tabela 2) e comprimento de plântulas (Figura 2A), foram inferiores àqueles demonstrados para a classe de sementes médias. Segundo Nakagawa (1999), alguns lotes de sementes podem apresentar maior massa seca de plântulas e menor germinação, sendo que a interpretação dos resultados deve ser cuidadosa, para evitar classificação incorreta do lote de sementes. Dessa forma, no contexto geral dos resultados, as sementes da classe de maior tamanho apresentaram menor vigor em relação às sementes de classificadas como médias.

As associações entre todas as características avaliadas podem ser observadas na análise de componentes principais (ACP). Os dois primeiros componentes principais foram capazes de explicar 95,95\% da variância contida nas variáveis originais, sendo que, 54,59\% é explicado pelo componente principal 1 (CP1) e 41,36\% foi explicado pelo componente principal 2 (CP2) (Figura 3).

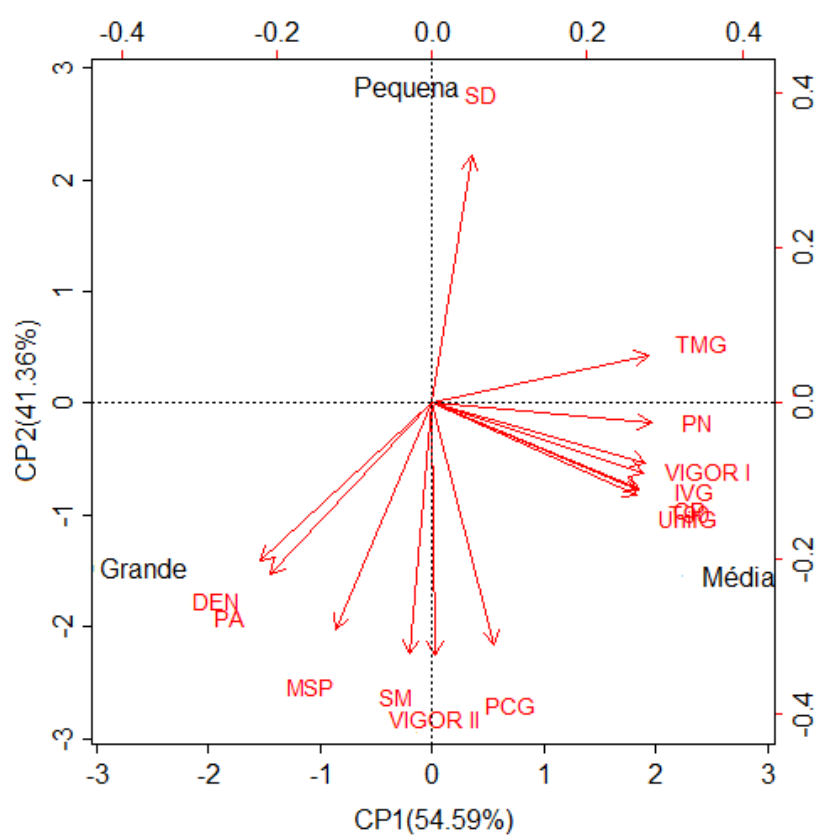

Figura 3. Análise dos principais componentes referente às classes pequena, média e grande de $P$. dubium e as suas associações com os parâmetros avaliados.

No primeiro componente principal é possível identificar a associação positiva entre as variáveis PN, IVG, TMG, T90, UnifG, CP e VIGOR I. No contexto de vigor, esses parâmetros são de grande importância e necessários para que um lote tenha melhor desempenho durante a emergência. Essas variáveis apresentaram maior associação com a classe das sementes médias, indicando o maior potencial fisiológico dessa classe de sementes. Por outro lado, a PA, MSP e DEN apresentam associação positiva entre si, e com as sementes da classe de tamanho grande. Considerando isoladamente a variável SD deste componente, verifica-se que essa possui forte associação com a classe de sementes pequenas. 
Em relação ao segundo componente principal é possível identificar que pelo fato de as sementes da classe pequena apresentarem menor massa, a MSP e o VIGOR II são consequentemente, negativamente correlacionados com essa classe de sementes, ou seja, as sementes com menor massa possuem menor capacidade de formação de plântulas vigorosas.

Dessa forma, o presente estudo demonstrou as diferenças intrínsecas dentro de um lote de sementes de $P$. dubium, sendo possível identificar as diferenças nas características biométricas, na qualidade fisiológica, intensidade de dormência, e as relações entre essas características, auxiliando na tomada de decisão durante o beneficiamento e a futura utilização à campo.

\section{CONCLUSÕES}

A classe de sementes média de $P$. dubium apresenta maior potencial fisiológico.

A classe de sementes pequena de $P$. dubium possui maior intensidade de dormência.

A classe de sementes grande de $P$. dubium tem maior capacidade para formação de plântulas com maior massa seca.

\section{AGRADECIMENTOS}

Os autores agradecem a Universidade Comunitária da Região de Chapecó - Unochapecó por ceder o espaço e material para elaboração da pesquisa e a equipe do Viveiro Florestal Universitário da Unochapecó pelo auxílio na coleta de sementes.

\section{REFERÊNCIAS}

ABDUL-BAKI A.A.; ANDERSON J.D. Vigour determination in soybean by multiple criteria. Crop Science, v.13, p.630-633, 1973.

ALMEIDA, J.P.N. et al. Estresse hídrico e massa de sementes na germinação e crescimento de plântulas de Amburana cearensis (Allemão) A.C. Smith. Revista Ciência Agronômica, v.45, n.4, p.777-787, 2014.

ALVES, E.U. et al. Influência do tamanho e da procedência de sementes de Mimosa caesalpiniifolia benth. sobre a germinação e vigor. Revista Árvore, v.29, n.6, p.877-885, 2005.

ANDRADE, G.C.D. et al. Seed reserves reduction rate and reserves mobilization to the seedling explain the vigour of maize seeds. Journal of Seed Science, v.41, n.4, p.488-497, 2019.

ATTRI, V. et al. Influence of seed size and pre-sowing treatments on germination parameters of Sapindus mukorossi Gaertn under laboratory condition. International Journal of Current Microbiology and Applied Sciences, v.6, n.10, p.2788-2799, 2017.
BEWLEY, J.D. et al. Seeds: physiology of development, germination and dormancy.3.ed. New York: Springer, 2013.

BISPO, J.S. et al. Size and vigor of Anadenanthera colubrina (Vell.) Brenan seeds harvested in Caatinga areas. Journal of Seed Science, v.39, n.4, p.363-373, 2017.

BISHT, V.K. et al. Variations in the seed germination in Sapindus mukorossi in relation to tree age dependent seed vigour. National Academy Science Letters, v.39, n.5, p.379-382, 2016.

BRASIL. Ministério da Agricultura e Reforma Agrária. Regras para Análise de Sementes. Departamento Nacional de Defesa Vegetal, 2009.

BRASIL. Ministério da Agricultura, Pecuária e Abastecimento. Instruções para análise de sementes de espécies florestais. Ministério da Agricultura, Pecuária e Abastecimento. Secretaria de Defesa Agropecuária/Coordenação Geral de Apoio Laboratorial Mapa/SDA/CGA, 2013.

CARVALHO, P.E.R. Espécies arbóreas brasileiras. Brasília: Embrapa Informação Tecnológica, 2003.

CARVALHO, N.M.; NAKAGAWA, J. Sementes: ciência tecnologia e produção. 4.ed. Jaboticabal: FUNEP,2012.

CASTAN, D.O.C. et al. Vigor-S, a new system for evaluating the physiological potential of maize seeds. Scientia Agricola, v.75, n.2, p.167-172, 2018.

CORADIN, L. et al. Espécies nativas da flora brasileira de valor econômico atual ou potencial. Brasília: Ministério do Meio Ambiente, 2011.

DIAS, P.C. et al. Estaquia e miniestaquia de espécies florestais lenhosas do Brasil. Pesquisa Florestal Brasileira, v.32, n.72, p.453-462, 2012.

FARIA, J.C.T. et al. Substratos alternativos na produção de mudas de Mimosa setosa benth. Ciência Florestal, v.26, n.4, p.10751086, 2016.

FAROOQ, M. et al. Thermal hardening: a new seed vigor enhancement tool in rice. Journal of Integrative Plant Biology, v.47, n.2, p.187-193, 2005.

KRZYZANOWSKI, F.C. et al. A. A alta qualidade da semente de soja: fator importante para a produção da cultura. 2018. Disponível em: https://ainfo.cnptia.embrapa.br/digital/ bitstream/item/177391/1/CT136-online.pdf

LABOURIAU, L.G. A germinação de sementes. Whashington: OEA, 1983.

MARCOS-FILHO, J. Teste de envelhecimento acelerado. Vigor de sementes: conceitos e testes. Londrina: ABRATES, 1999.

MARCOS-FILHO, J. Fisiologia de sementes de plantas cultivadas. 2.ed. Londrina: ABRATES, 2015.

MAGUIRE, J.D. Speed of germination aid in selection and evaluation for seedling emergence and vigor. Crop Science, v.2, n.2, p.176-177, 1962. 
MISSANJO, E.; MKWEZALAMBA, I. Influence of seed weight variation on seedling emergence and growth of Acacia nilotica Journal of Basic and Applied Research International, v.2, n.3, p.85-94, 2015.

MISSANJO, E.; MAYA, C. Survival and Growth Response of Seedlings to Seed Size Variation of Albizia lebbeck (L.) Benth. Journal of Agriculture and Ecology Research International, v.3, n.2, p.67-74, 2015.

MTAMBALIKA, K. et al. Effect of seed size of Afzelia quanzensis on germination and seedling growth. International Journal of Forestry Research, v.2014, p.1-7, 2014.

MÜLLER, E.M. et al. Maturação e dormência em sementes de Peltophorum dubium (Spreng) Taub. de diferentes árvores matrizes. Iheringia. Série Botânica, v.71, n.3, p.222-229, 2016.

NAKAGAWA, J. Testes de vigor baseados no desempenho das plântulas. Vigor de sementes: conceitos e testes. Londrina: ABRATES, 1999.

NETO, A.R.; PAULA, R.C. Variabilidade entre árvores matrizes de Ceiba speciosa St. Hil para características de frutos e sementes. Ciência Agronômica, v.48, n.2, p.318-327, 2017.

PEREIRA, W.A. et al. Influência da disposição, número e tamanho das sementes no teste de comprimento de plântulas de soja. Revista Brasileira de Sementes, v.31, n.1, p.113-121, 2009.

PEREIRA, W.A. Dinâmica de reservas das sementes de soja durante o desenvolvimento de plântulas de diferentes cultivares comerciais. Journal of Seed Science, v.37, n.1, p.63-69, 2015.

PIROLI. E. L. et al. Germinação de sementes de canafístula Peltophorum dubium (spreng.) Taub. tratadas para superação da dormência. Colloquium Agrariae. v.1, n.1, p.13-18, 2005.

$R$ CORE TEAM. R: A language and environment for statistical computing. Vienna: R Foundation for Statistical Computing, 2019.

RUBIO DE CASAS, R. et al. Global biogeography of seed dormancy is determined by seasonality and seed size: a case study in the legumes. New Phytologist, v.214, n.4, p.1527-1536, 2017.

SILVA, K.B. Qualidade fisiológica de sementes de Sideroxylon obtusifolium (Roem. \& Schult.) Penn. classificadas pelo tamanho. Revista brasileira de Biociências, v.13, n.1, p.1-4, 2015.

SILVA, A.C.D. et al. Tamanho da semente e substratos na produção de mudas de açaí. Advances in Forest Science, v.4, n.4, p.151-156, 2017.

SILVA, L.J.D. et al. SeedCalc, a new automated R software tool for germination and seedling length data processing. Journal of Seed Science, v.41, n.2, p.250-257, 2019.

SOUZA, A.G. et al. Correlation of biometrical characteristics of fruit and seed with twinning and vigor of Prunus persica rootstocks. Journal of Seed Science, v.38, n.4, p.322-328, 2016.

SOUZA, A.B. et al. Optimization of germination and initial quality of seedlings of Prunus persica tree rootstocks. Journal of Seed Science, v.39, n.2, p.166-173, 2017.
WANG, B.; IVES, A.R. Tree-to-tree variation in seed size and its consequences for seed dispersal versus predation by rodents. Oecologia, v.183, n.3, p.751-762, 2017. 